\title{
LA EXPRESIÓN DE EMOCIONES A TRAVÉS DE LA METÁFORA: ANÁLISIS CONTRASTIVO ESPAÑOL-ITALIANO
}

\section{EXPRESSION OF EMOTIONS THROUGH THE METAPHOR: SPANISH-ITALIAN CONTRASTIVE ANALYSIS}

\author{
Ma CÁndida Muñoz Medrano \\ Università degli Studi di Catania \\ medra@libero.it
}

Enviado: 27/05/2018

Aceptado: 06/09/2019

\begin{abstract}
Resumen
Tras realizar una aproximación a la relación entre metáfora y fraseología, nos centramos en cómo se produce la conceptualización de determinadas emociones en español e italiano. Realizamos un análisis a través de un corpus de unidades fraseológicas, que contienen fundamentalmente metáforas que expresan emociones derivadas de experiencias protagonizadas por el propio cuerpo. La similitud de tales experiencias sirve para comprobar que en ambas culturas no existen diferencias significativas en cuanto a la expresión de las emociones analizadas. El objetivo perseguido es comparar el modo en que estas emociones se conceptualizan a través de estructuras metafóricas. Para tal propósito aplicamos los principios teóricos generales de la semántica cognitiva a los datos que resultan de la fraseología que conceptualiza estas emociones y organizamos unos modelos icónicos jerarquizados, formados por archimetáforas y metáforas particulares, procedimiento que podría resultar relevante también en otros campos nocionales.
\end{abstract}

\begin{abstract}
After an approach to the important of the metaphor in phraseologism, we show how the conceptualization of emotions in both languages is fundamentally structured by metaphors consisting of mappings from the domain of body and bodily experiences. It found that between these two languages and the related cultures doesn't exist a significant differences. At the second time, the present study illustrates in detail the metaphors used by Italian and Spanish languages to express emotions like fear, love, happiness, sadness, anger. Our intention is compare the ways how these emotions are conceptualized in both languages through metaphorical structures. Then, we apply the general theoretical principles of cognitive semantics to the data taken from the phraseology on fear, love, happiness, sadness and anger. We intend to organize a hierarchic set of iconic models, archimetaphors and particular metaphors, that would be relevant also in many other notional fields. But at the same time we find out some contradictions between the projection process, as described by cognitive semantics.
\end{abstract}

Para citar este artículo / To cite this article: Muñoz Medrano, Ma Cándida (2019). la expresión de emociones a través de la metáfora: análisis contrastivo español-italiano. ELUA, 33: 141-156. doi: 10.14198/ELUA2019.33.7

Enlace / Link: http://dx.doi.org/10.14198/ELUA2019.33.7 
PALABRAS CLAVE: metáfora conceptual, manifestaciones lingüísticas, cultura, unidad fraseológica.
KEYWORDS: conceptual metaphor, linguistic manifestations, culture, phaseologism.

\section{FRASEOLOGÍA Y METÁFORA}

El interés por el estudio de la fraseología comenzó a surgir a finales del siglo XX, durante mucho tiempo esta parcela de la lingüística quedó relegada a otras disciplinas como la lexicografía y la paremiología (Navarro: 2016; Durante: 2014). El término fraseología fue acuñado en 1909 por Ch. Bally, que le dio el valor con el que se sigue empleando actualmente. Desde los años 40, y sobre todo a partir de la década de los 60 , el lingüista ruso V.V.Vinogradov recogió la herencia de Ch. Bally y se convirtió en máximo investigador de la fraseología en la antigua URSS, donde se originó la fraseología como disciplina científica. En esa época la lingüística soviética estableció las bases teóricas para su estudio y a partir de entonces se desarrolló de forma diferente en otros países y según distintas escuelas. Los lingüistas soviéticos analizaron los rasgos de las unidades fraseológicas ${ }^{1}$, su función y su origen desde tres puntos de vista:

- Las propiedades internas de la UF: las peculiaridades fonéticas, morfemáticas, sintagmáticas y lexemáticas de sus componentes y las relaciones que se establecen entre ellos.

- El papel de las UFS en el contexto: sus funciones como clase de palabras, su valencia sintáctica y semántica y propiedades expresivas y estilísticas y sus posibilidades de variación.

- Las relaciones con otros subsistemas de la lengua, o sea el sistema léxico y el sistema sintáctico y, por ello, con las combinaciones no fraseológicas, o combinaciones libres.

Los presupuestos establecidos en las investigaciones soviéticas tuvieron continuidad en los trabajos sobre fraseología llevados a cabo en los países de Europa Oriental, sobre todo en la RDA (República Democrática Alemana), y también en otros países como Cuba. En particular, las autoras cubanas A. M. Tristá y Z. Carneado, que trabajaron durante algún tiempo en la antigua URSS, realizaron, a partir de 1976, varios trabajos como se ha señalado anteriormente, que abarcaban aspectos tan variados como la tipología de UFS, las fuentes de las cuales provienen, la fraseografía y los diccionarios. Estas publicaciones fueron fundamentales en la elaboración de trabajos posteriores que verían la luz en España.

En Europa occidental se obvia el concepto de fraseología como disciplina independiente y se prefiere acomodar el análisis de las UFS al efectuado por los funcionalistas. Autores como E. Coseriu (1986) y A. Zuluaga (1980) le dedican una especial atención. Coseriu acuña en 1964 el término discurso repetido, que recoge las unidades de la fraseología, en oposición a la técnica libre del discurso. En 1980 Zuluaga publica su tesis doctoral sobre las expresiones fijas del español, incorporando la metodología de otros autores muy conocidos como Casares, Coseriu y Bally y, sobre todo, hace referencia a las propiedades más importantes de las UFS, la fijación y la idiomaticidad, presentando, además, una clasificación y un estudio de las varias categorías que las representan. Actualmente el trabajo de Casares, Introducción a la lexicografía moderna (1993), sigue siendo un pilar fundamental en el estudio de la fraseología. El volumen se divide en seis capítulos dedicados a las locuciones, frases proverbiales, refranes y modismos en que

1 A partir de ahora UFS 
el autor distingue entre dos grandes grupos, el de las locuciones y el de los refranes. El mérito de este trabajo consiste en constituir la primera clasificación global que se conoce de las expresiones fijas. En los Estados Unidos el estudio de la fraseología en cuanto componente fundamental de la gramática de una lengua fue reconocido por la gramática cognitiva a partir de los 90 . Hasta entonces se consideraba como un elemento incómodo para su estudio, tanto para los estructuralistas, debido a su carácter asistemático, como para los generativistas, al ir en contra de la capacidad generativa de la gramática a partir de un número limitado de reglas. En España el interés por la fraseología surgió hacia mediados de los 90, a pesar de los estudios que en los años cincuenta llevó a cabo J. Casares (1993), cuyas ideas supusieron un avance muy importante en el intento de delimitar y clasificar estas construcciones pluriverbales (Corpas Pastor, 2000:32-35). En 1980 Zuluaga, heredero de Casares, contempla las expresiones fijas como reproducciones en bloque. Para este autor, la reproducibilidad es un factor constitutivo de las UFS junto a su idiomaticidad. En 1996 sale a la luz el manual de fraseología española de G. Corpas, en que la autora define las UFS (1996: 290) como “[...] unidades léxicas formadas por más de dos palabras gráficas [...]” y se caracterizan por su alta frecuencia de uso, y de coaparición de sus elementos integrantes; por su institucionalización, entendida en términos de fijación y especialización semántica; por su idiomaticidad y variación potenciales, así como por el grado en el cual se dan todos estos aspectos en los distintos tipos. La fijación, como advierte Corpas, es una característica relativa, puesto que muchas construcciones fijas admiten cierta variación en sus componentes. A partir de 1996 empiezan a tener lugar en Madrid, como en otras partes de España, congresos internacionales sobre la paremiología y la fraseología. De ahí la aparición de numerosas monografías sobre el tema, entre las que hay que destacar la de Ruiz Gurrillo Aspectos de fraseología teórica española (1997), donde la autora define las expresiones fraseológicas como complejos sintagmáticos fijos. En este trabajo se reflexiona sobre el estatus teórico de la disciplina y los aspectos sintácticos y pragmáticos de las UFS a través de un corpus de citas del español oral.

El Manual de fraseología españolade Corpas Pastor, junto con el de Martínez Marín (2000: 249-260), marcó un punto de partida importante en los estudios posteriores sobre fraseología en España. En apenas dos décadas la fraseología, en un primer momento una subdisciplina de la lexicología, se afirma como disciplina en toda regla graciasal interés que despertó en muchos estudiosos europeos, especialmente por parte de las corrientes lingüísticas y pragmáticas orientadas hacia el estudio de las UFS en el contexto.

Entre los distintos y relevantes aspectos fraseológicos investigados que más nos interesan en esta ocasión se encuentra una serie de aspectos concretos de la definición lexicográfica de las UFS, como sus posibles variantes formales (Montoro 2004), su caracterización pragmática (Penadés 1999) y gramatical y el uso de la metáfora en las locuciones verbales metafóricas, que más adelante vamos a tratar. Por ello, se hace necesario abordar el concepto de metáfora, ya que es un ingrediente fundamental de las UFS que forman parte del corpus que se va a analizar. Es necesario, por tanto, precisar qué tipo de metáfora participa en la construcción de las UFS en general y en las UFS que estudiamos en particular.

La primera aproximación al estudio de la metáfora tiene lugar en 1980,cuando los autores Lakoff y Johnson publicaron el volumen Metaphors We Live By,cuyos postulados suponían una ruptura con las teorías que hasta entonces se habían desarrollado sobre la metáfora. A partir de estos autores, la concepción clásica de la metáfora tal como la entendían Aristóteles 
y Quintiliano ya no sería útil para explicar estas estructuras. Lakoff y Johnson no entendían la metáfora ni como un artificio retórico ni como un instrumento finalizado a conseguir objetivos puramente ornamentales, tampoco sería una figura de estilo propia del lenguaje literario y destinada a producir efectos estéticos, por el contrario estaría relacionada con el lenguaje cotidiano. Antes de que estos autores dieran a conocer sus estudios, la metáfora era un asunto de interés periférico, siendo a partir de la década de los 80 cuando comenzaron a proliferar trabajos sobre su significado, entonces se comprobaría que gran parte de las metáforas tradicionalmente convencionales son generadas por estructuras básicas de nuestra experiencia y de nuestra manera de pensar. Esta idea renovada del concepto de metáfora la debemos al desarrollo del cognitivismo en el ámbito de la filosofía del lenguaje, disciplina que posibilitó que no volviera a considerarse como una figura estilística de cuyo estudio debía ocuparse la retórica y la teoría literaria. Jäkel (2002: 21) se expresaba en estos términos al respecto:

Linguistic metaphor is not an exceptional matter of poetic creativity or excessive rhetoric. In perfectly ordinary everyday language (as well as in highly specialized expert discourse), conventional metaphors are abundant. Therefore, linguists have to face the task of accounting for them as part of our general linguistic competence.

Con este cambio en las consideraciones tradicionales de la metáfora, esta se convertiría para la lingüística en una de las causas principales del cambio semántico².

Según la lingüística cognitiva, la metáfora sería el resultado de un proceso mental a través del cual se llegan a entender ciertos aspectos abstractos de la experiencia en términos de otros aspectos más concretos, como aduce Nubiola (2000:73-84). Los mecanismos que rigen dichos procesos metafóricos no están en el lenguaje sino que se ubican en nuestro sistema conceptual, muy ligado a la cultura. A raíz de esto, resulta que nuestra mente estructura el mundo a partir de metáforas comprensibles por los miembros de una misma comunidad lingüística. Por consiguiente, las UFS, y en concreto las locuciones verbales metafóricas, poseen un significado translaticio que se basa en un proceso de analogía: valga como ejemplo la locución quedarse yerto (asustarse en grado sumo), en la que se observa una semejanza entre el significado del vocablo yerto, tieso o rígido, especialmente a causa del frío o de la muerte, y la transformación que experimenta una persona cuando tiene mucho miedo (pudiendo llegar a la inmovilidad). A partir de la forma léxica yerto se designa otro concepto que ostenta una funcionalidad parecida, y esto se hace eligiendo una determinada forma léxica para expresar un concepto que comparte algunas características semánticas con el concepto más común designado por la forma léxica yerto. En este sentido, Iñesta y Pamies (2002: 57) efectúan la siguiente aclaración:

...la función de la metáfora en los procesos cognitivos...[es un] recurso que facilita la conceptualización, estructuración del significado, mediante la proyección de un concepto sobre otro y, por lo tanto,... nuestra comprensión del mundo físico, el movimiento, etc. son fuentes de metáforas: a partir de lo más cercano, experiencial, se explicaría lo más lejano. Así por ejemplo, realidades abstractas se comprenden mediante la metáfora en términos de realidades concretas, tomadas de la experiencia cotidiana.

2 Samaniego (1998), trata las distintas posturas que se han adoptado al abordar el concepto de metáfora y los problemas de la traducción de estas estructuras. 
En la teoría sobre la metáfora de Lakoff y Johnson, estas estructuras se utilizan con la finalidad de explicar aquellas realidades más abstractas e intangibles, según venimos diciendo, proyectando rasgos de elementos que se pueden percibir. Por tanto, se trata de realizaciones lingüísticas de estructuras metafóricas mentales consideradas por este motivo como metáforas conceptuales (Lakoff 1991: 219). Los autores (1987: 276) sostienen que toda metáfora posee un dominio de origen, uno de llegada, y una proyección: el dominio de origen es concreto y procede de la experiencia real, mientras que el dominio de llegada es abstracto (Lakoff 1979: 245; Taylor 2002: 590). La proyección metafórica es la aproximación de estos dos dominios conceptuales, distintos, a través de un transvase de conocimientos del uno al otro con la intención de crear relaciones ontológicas entre las entidades que pertenecen a los dos dominios (Lakoff y Johnson 1998: 48-50; Chamizo Domínguez, 2005). Tal proyección es el origen del fenómeno metafórico, que tiene lugar en el ámbito de la conceptualización; así se distingue entre las metáforas conceptuales o esquemas idealizados, que sirven como base en la conceptualización de un fenómeno o grupo de fenómenos, como la vida es una tombola, y las expresiones metafóricas o epifenómenos lingüísticos que revelarían las metáforas conceptuales, como por ejemplo este asunto ha tocado fondo. La metáfora no corresponde a una expresión o a una palabra, sino a la equivalencia esquemática entre la base experiencial de una tombola y el dominio conceptual de la vida. La correspondencia es convencional, es decir, es una parte fija de nuestro sistema conceptual, una de nuestras maneras convencionales de conceptualizar la vida, ya que el sistema conceptual humano está corporeizado y por medio de este se desarrollan patrones o esquemas a partir de nuestra experiencia (Lakoff y Johnson: 1986; 1987). Los autores nos hablan de "modelos cognitivos idealizados", que son conceptos cognitivos que no están presentes en la naturaleza, sino en el pensamiento humano. Estos modelos cognitivos idealizados son las cuatro formas de subdividir el conocimiento de nuestras experiencias cotidianas: la organización proposicional, las proyecciones metafóricas, las proyecciones metonímicas y la esquematización de imágenes. Los esquemas de imágenes facilitan la conceptualización de lo psíquico (sentimientos y sensaciones), ya que se basan principalmente en la manipulación de objetos, en movimientos corporales y en interacciones conceptuales (Montoro del Arco, 2007: 131).

Partiendo de estas teorías, el objetivo del presente trabajo es explorar las UFS españolas e italianas que verbalizan una serie de emociones que vamos a tratar a continuación, además de su construcción, la formación de imágenes y metáforas, y las correspondencias en ambas lenguas.

\section{LAS UFS METAFÓRICAS Y LA EXPRESIÓN DE LAS EMOCIONES: MIEDO, IRA, AMOR, FELICIDAD Y TRISTEZA}

La denominación unidad fraseológica, propuesta por Corpas, representa un término amplio que engloba los diferentes tipos sin que se pueda confundir con ningún subtipo, como en el caso de las locuciones; tienen el estatus de unidades lingüísticas y funcionan como tales en diferentes niveles gramaticales. Las locuciones verbales se pueden definir como unidades fraseológicas del sistema de la lengua que no constituyen elementos racionales. Al igual que las UFS en general, las locuciones están caracterizadas esencialmente por dos rasgos, es decir la fijación y la idiomaticidad (Muñoz Medrano, 2012: 30-37), aunque como subraya Ruiz Gurillo (2006: 13-18) la manifestación de estas propiedades es una cuestión 
de grado. Las locuciones verbales están constituidas por un núcleo verbal acompañado de complementos. Desde el punto de vista sintáctico expresan procesos y actúan como los predicados, con o sin complementos. Según G. Corpas Pastor presentan una gran diversidad morfosintáctica.Desde el punto de vista semántico tienen un significado figurado, que se expresa a través de una metáfora connotativa. Por esta razón denominamos locuciones verbales metafóricas a todas las UFS que forman parte de nuestro corpus.

Ya en los años inmediatamente posteriores a la propuesta inicial de la Teoría conceptual de la metáfora (Lakoff y Johnson, 1980), se abogó por el papel decisivo que juegan las experiencias corpóreas en la formación del significado, y con ello se convino en que al compartir todos los seres humanos esencialmente las mismas características corpóreas, las metáforas conceptuales podrían asimismo compartir modelos universales. Sin embargo, algunos estudios más recientes (Gibbs, 1999; Rossetti, 2006; Kövecses, 2005) muestran que la cultura desempeña un importante papel en la formación de metáforas y que esos universales no siempre se dan en todas las lenguas. Según Kövecses (2010), aunque existen los universales en las metáforas conceptuales, hay parcelas con características culturales específicas (Kövecses, 2010). Algunos ejemplos son los trabajos de Deignan (2003), Özçaliskan (2003) y de Siqueira y Lamptrecht (2007), que dan a conocer cómo el inglés y el chino usan "calor" como dominio fuente para expresar rabia, sin embargo las metáforas utilizadas en inglés sugieren un "líquido caliente", mientras que las actualizaciones en chino indican un "gas caliente". Deignan (2003) aduce que existen dos factores subyacentes a esas diferencias entre lenguas: por un lado, las diferentes culturas deben tener diferentes creencias sobre las características del dominio fuente, y por otro, un dominio fuente puede ser menos saliente en diferentes culturas (Deignan, 2003, p.257). Jakobson y Halle (1971) sostenían que el pensamiento metafórico posee una base biológica, aunque al mismo tiempo toda comunidad pueda construir sus propios sistemas de clasificación; y tanto las categorías de pensamiento como los campos semánticos que las contienen estarán presentes implícitamente en las metáforas a las que se conectan los unos a los otros. Al mismo tiempo, las metáforas que usan las lenguas tienen que obedecer a las reglas que establecen la adecuación de la translación del significado. Por lo que respecta a las UFS del español y del italiano, convenimos en que ambas lenguas también usan "calor" como dominio fuente para la expresión de la rabia, así lo demuestran las siguientes UFS: echar fuego por los ojos, echar humo, dare in escandescenza, sprizzare rabbia dagli occhi, fare fuoco e fiamme. A su vez, al miedo en ambas lenguas se le relaciona con el cuerpo( Rodríguez-Simón y Pamies, 1998: 155-170), que experimenta reacciones fisiológicas, transformaciones físicas y sensaciones extrañas: ciscarse de miedo, encogérsele el ombligo a alguien, entrar un sudor frío, palidecer de miedo, quedarse yerto, temblar las carnes, battere $i$ denti di/per la paura, diventare bianco per la paura, farsela addosso, sotto dalla paura, sentire le gambe fare giacomo giacomo, sentire il collo in gola, sentirsi rimescolare o torcere le budelle, sudare freddo, tremare di/ per paura. El miedo en las dos culturas provoca la huida: huir como alma que lleva el diablo, poner los pies en polvorosa, salir por pierna, acappare a rotta di collo/gambe, darsela a gambe, fuggire all'impazzata/come un fulmine/come un razzo, fuggire come una lepre.

Se observa que la mayoría de las UFS que se han citado toma como punto de referencia el cuerpo, centro desde el que vemos, oímos o tocamos el mundo que nos rodea y que conformaun espacio empírico que percibimos de forma muy relevante. Luque Durán (2004: 513) comenta que las partes vitales del cuerpo se ubican en el centro, y se proyectan en las 
emociones y facultades intelectuales del ser humano. Según Jäkel (2003: 158) este esquema responde a las metáforas siguientes:"centro es positivo", "periferia es negativo", "lo importante es central" y "lo accesorio es periférico". Se comprueba que se cumple esta máxima en un grupo amplio de UFS que en italiano y en español expresan emociones, como por ejemplo: encogérsele el ombligo a alguien, entrar/llegar muy adentro, llegar a las telas del corazón, entrare dentro/toccare nel profondo, far battere il cuore. La emoción expresada se produce en el centro del cuerpo, y el corazón se proyecta hacia la profundidad del sentimiento amoroso, si bien se trata al mismo tiempo del órgano con más representatividad para designar metafóricamente el amor; el corazón es un recipiente (Lakoff/Johnson 1986: 67) que se abre o salta para expresar esta emoción. Dichas unidades activan la metáfora "el amor es un movimiento hacia adentro".

Pamies postula que las teorías cognitivas sobre la metáfora han extendido considerablemente el campo que esta abarca en la formación de las UFS; sin embargo, aduce que no todos los conceptos pueden ser metafóricos: "tiene que existir previamente alguna 'materia prima' semántica irreductible, de naturaleza no-metafórica, a partir de la cual pueda comenzar la cadena de proyecciones de un concepto sobre otro" (2002: 9)

En definitiva nos podemos preguntar, tal como se plantea Gibbs (1994: 44 y ss), cuál es el origen de las metáforas y por qué se eligen determinadas construcciones en beneficio de otras, pero estas respuestas formarían parte de otra investigación por su complejidad y extensión, y no podemos incluirlas en este estudio.

Iñesta y Pamies (2002) manifiestan ciertas reticencias ante los postulados de Lakoff y Johnson: si bien consideran que a partir de metáforas convencionales como las que se utilizan para expresar miedo se pueden analizar y clasificar las UFS, la terminología empleada por Lakoff y Johnson del tipo "el cuerpo es un recipiente" o "arriba es bueno" no es adecuada, principalmente porque no se puede aplicar como criterio seguro para clasificar todas las UFS al no poder reducirse numerosas estructuras a estas afirmaciones; algunos ejemplos son las siguientes UFS: avere le chiavi del cuore di qualcuno, avere la puzza sotto il naso, montarsi la testa, subirsele a alguien los humos a la cabeza. Sin embargo, el esquema "menos es abajo", "infeliz es abajo" estaría en la base de expresiones como no poder dar un paso, poner los pies en polvorosa, mirar de arriba abajo, salir por pierna, dársela a gambe, guardare dall'alto in basso, sentirsi le gambe fare giacomo giacomo. El esquema"feliz es arriba" es el que explicaría expresiones como llegar a las telas del corazón, arrivare/giungere al cuore, avere le chiavi del cuore di qualcuno.

\subsection{La metáfora en la formación de las UFS que verbalizan emociones}

Como ya señalaba Wotjak (1985:217), las UFS atraen la atención del receptor y dan forma a valoraciones subjetivas que el hablante emite, ya que resultan ser muy expresivas, connotativas y valorativas. Las metáforas ${ }^{3}$ que conforman las UFS son, por tanto, las herramientas cognitivas más utilizadas en su formación, y a través de la cuales proyectamos patrones que derivan de nuestra experiencia con la intención de estructurar otra esfera y establecer así una relación entre dos dominios, uno más concreto y otro más abstracto, esto es, se proporciona la comprensión de un tipo de experiencia a través de imágenes (Lakoff

3 Se aconseja la lectura del trabajo de Pamies, A (2016) para empliar este tema. 
\& Jonson, 1991 (1980): 195). Se designan por tanto a través de las metáforas conceptos abstractos por medio de otros de carácter más concreto y que, en definitiva, pueden ser transportados a los denominados universales lingüísticos.

Entre las locuciones verbales metafóricas existe un conjuntode unidades que alberga un nivel alto de motivación, y a su vez se emparentan con metáforas convencionales que responden a unos patrones ya existentes, como afirmaba Lakoff (1987:438). Son al mismo tiempo estructuras insconscientes y automáticas que al estar sancionadas por su continuo uso responden a las mismas normas que el lenguaje literal. Existe por tanto una sistematicidad y productividad en los mecanismos de creación, comprensión y uso de este tipo de estructuras. Algunos autores como Molina Plaza (2008:208) han postulado que la fraseología comparte con las metáforas una dificultad translativa y, efectivamente, comprobamos que la traducción de las UFS lleva aparejada la traducción de una metáfora.

Las estructuras, UFS, de las emociones que vamos a analizar poseen una fuente común para la producción metafórica que se basa en la percepción, las facultades psicomotrices y la experiencia corporeizada, consideraciones ya establecidas por Lakoff (1987: 12) y la semántica cognitiva. En estos términos se expresa Pamies al respecto: "determinados clichés mentales permiten proyectar nuestros conocimientos básicos adquiridos por medios psicosensoriales y vivenciales hacia otros dominios más lejanos y/o abstractos" (2002: 10).

Para el autor, los componentes básicos que intervienen en la composición de una imagen arquetípica muy productiva deberían reaparecer en el análisis de otras imágenes arquetípicas productivas, y la mejor manera que tienen de hacerlo las UFS es a partir de las nociones expresadas por estas (dominio meta). A continuación los autores desglosan cada categoría en consideración a la imagen que la inspira (dominio fuente o grupo de dominios fuente); a este nivel lo denominan Pamies/Iñesta (2002) modelo icónico. Por ejemplo, el dominio meta de la metáfora echar fuego por los ojos es la ira-cólera, y estaría basada en un modelo icónico o en una combinación de dominios fuente (movimiento+cuerpo). En estos dominios se incluyen archimetáforas como "la ira es un movimiento corporal hacia arriba", que a su vez incluye metáforas como subirsele a alguien la sangre a la cabeza, cuya traducción a italiano es montare la testa. Por su parte, otras estructuras como echar humo, echar rayos, echar venablos, (estar) hecho una fiera, echar espuma de rabia, escupir veneno y bilis, estar que echa rayos, estarían también dentro de la archimetáfora "movimiento hacia afuera", al igual que echar fuego por los ojos, en italiano sprizzare rabbia dagli occhi. Ambas archimetáforas pertenecerían al mismo modelo icónico: cuerpo + movimiento.

Hay que precisar que frecuentemente un mismo modelo icónico puede subdividirse en varias archimetáforas, como subgrupo o nivel intermedio entre el modelo icónico y la metáfora. Así, el modelo icónico que acabamos de aludir (cuerpo + movimiento) se podría subdividir en varias archimetáforas según representen un movimiento hacia arriba, hacia abajo, hacia fuera, hacia dentro, etc. Sin embargo, este modelo no puede aplicarse integralmente al corpus de UFS que se analiza en este trabajo, según se ha comprobado, por lo que nos limitamos a clasificar el mayor número de UFS que se agrupan en determinadas archimetáforas en las dos lenguas. A partir de unos modelos icónicos se formula un conjunto de archimetáforas y a partir de cada archimetáfora se clasifican UFS que expresan las siguientes emociones en español e italiano: miedo, amor, ira, felicidad y tristeza. De esta manera, un mismo modelo icónico incluye metáforas en principio muy distintas y así se explica el alto número de similitudes interlingüísticas entre UFS formalmente distintas pero cónicamente 
emparentadas. Se puede llegar a establecer muchas matizaciones y se multiplicará el número de dominios que podrían ser tenidos en cuenta, algo que no podemos tratar en este trabajo por motivos de espacio. Toda la fraseología cabe en alguna de las archimetáforas.

\subsection{Las emociones miedo, amor, ira, felicidad y tristeza}

Como ya afirmaba Humboldt (1990:91) las emociones son estados anímicos de duración más o menos breve muy ligados a experiencias y sensaciones corporales, una manera de responder directamente a tales estímulos espontáneos. Expresar emociones no es una tarea fácil para todos los hablantes, pero en muchos casos el uso de las UFS contrarresta en gran medida esa dificultad, precisamente por la intensidad que llevan consigo en su expresión, consiguiendo así el hablante acaparar la atención de su interlocutor. Las UFS con intensidad emotiva no cumplen la función de indicar que alguien está enfadado, está triste o tiene miedo sino más bien que esa persona está muy enfadada, tiene muchísimo miedo o está demasiado triste: echar fuego por lo ojos, llorar a moco tendido o quedarse yerto, son algunos de los numerosos ejemplos que podríamos traer a colación. Hay que distinguir entre las UFS que expresan solamente intensidad emotiva y las que, además, van acompañadas de valoraciones. Un grupo numeroso entre las locuciones que vamos a analizar expresa emociones de carácter negativo ${ }^{4}$, tal es la locución estar hecho un basilisco, que denota ira al mismo tiempo que transmite una valoración despectiva al compararse a la persona con el basilisco, un animal fabuloso al que se le atribuía la facultad de matar con la vista; otro ejemplo es la UF salir con el rabo entre las piernas, empleada para ridiculizar a una persona que siente mucho miedo, connotando su cobardía. Y este componente valorativo se halla en locuciones como ciscarse de miedo, huir como alma que lleva el diablo, andare a quattro zampe, avere paura della propria ombra.

Hemos seleccionado en este trabajo una serie de UFS que podrían ajustarse a lo que Dobrovol'skiï (1993:96) llama "universal fraseológico conceptual o cognitivo"5 por tratarse de la expresión de un instinto natural: sentir miedo, amor, ira, felicidad o tristeza. El estudio se ocupa solo de locuciones verbales metafóricas y se estructura el análisis según el modelo jerarquizado que diferencia "modelos icónicos" que incluyen varias "archimetáforas". Las categorías mediante las cuales se conforman los modelos icónicos se basan en nociones fuente que aparecen a veces combinadas entre sí. Nuestro criterio de selección ha sido la representatividad significativa y la alta frecuencia de uso de las UFS creadas a partir de estas emociones. Como se puede observar, el análisis semántico de la motivación figurativa de las locuciones verbales seleccionadas se ha efectuado a través de la explicitación de los esquemas de imágenes y las metáforas y metonimias conceptuales que subyacen a su significado idiomático. Recurrimos a la descripción de los esquemas de imágenes que intervienen en el desarrollo de dichos significados idiomáticos como estructuras que operan en nuestra percepción, organizan nuestras representaciones mentales en un nivel más general y abstracto que aquel en el que formamos imágenes mentales particulares. Se trataría de una serie de estructuras conceptuales que se vinculan con la percepción surgida del contacto físico y corporal con la realidad, según se verá a continuación.

4 El tema es tratado desde una perspectiva cognitivista en Pamies/Iñesta/Lozano (1998). Los autores analizan valoraciones implícitas en las unidades fraseológicas que han surgido sobre la base de metáforas (tiempo de perros, estar de un humor de perros, el negro de la uña, ponerse negro, etc.).

5 Es interesante la lectura del artículo de Ruiz Gurillo (2001:107-132) 
Después vamos a clasificar las UFS españolas e italianas que verbalizan estas emociones a fin de averiguar cuál es el modelo icónico y las archimetáforas más comunes en la expresión de las cinco emociones.

El corpus de UFS seleccionadas es el siguiente:

Achantar el rabo, atravesársele/ponérsele a alguien un nudo en la garganta, bailar en una pata (Can. Beber los vientos por otra persona, brincarle dentro del pecho/del corazón, (tener) cara de aleluya, ciscarse de miedo, (ser) como niño con zapatos nuevos, chiflarsel chalarse por, dar alguien saltos/brincos de alegría/de contento.

Echar el bodegón por la ventana, echar fuego por los ojos, echar humo, echar rayos, echar venablos, (estar) hecho una fiera, echar espuma de rabia, escupir veneno y bilis, encogérsele a alguien el ombligo, erizársele el cabello a alguien, estar que echa rayos, estar muerto de miedo, estar colado, estar encoñado, entrar/llevar/sentir algo muy adentro, estar como unas castañuelas, estar alguien hecho una Magdalena.

Helársele la sangre a alguien, huir como alma que lleva el diablo, no caber en sí, írsele a alguien la sangre a los talones/a los zancajos.

Llevarse un susto padre, llegarle algo a alguien a las telas del corazón, llevarse a alguien el demonio/los demonios/todos los demonios, llorar alguien a lágrima viva,llorar a moco tendido, llorar como una Magdalena.

No llegarle a alguien la camisa al cuerpo.

Ofenderse del aire.

Perder los estribos, perder la cabeza, pillar un susto, poner los pies en polvorosa, ponerse de los nervios, poner negro a alguien una cosa, ponerse amarillo, ponerse pálido, ponerse blanco como la cera, ponerse blanco como el papel, ponérsele a alguien la carne de gallina.

Quedarse helado, quedarse sin sangre, quedar petrificado de miedo, quedare sin aliento, quedarse yerto.

Montar en cólera.

Revolvérsele a alguien la bilis.

Sacar a alguien de sus casillas, sacar alguien de quicio, saltársele a alguien las lágrimas, salir por pierna, salir con el rabo entre las pienas, sentir/tener sudores fríos, sudar de miedo, ser presa del pánico. subirsele a alguien la sangre a la cabeza.

Tener el corazón en un puño, tenerlos por corbata, tomarle miedo (a alguien/a algo), temblar como un pajarito, temblar como una liebre cazada, temblar las carnes, tener un miedo cerval, tirar piedras, subirse a la parra.

Acappare a rotta di collo/gambe, aver paura anche dell'aria, avere paura anche a respirare, avere/prendersi una fifa blu, avere paura della propria ombra, avere il cuore in gola, avere il batticuore, andare in bestia, andare pazzo/matto per qualcuno, andare a carponi/a quattro zampe, andare su tutte le furie, arrivare/giungere al cuore, avere le chiavi del cuore di qualcuno, avere una cotta per qualcuno, avere il dente avvelenato con, avere un diavolo per capello, avere un nodo in gola.

Battere il cuore, battere $i$ denti di/per la paura, da far paura, entrare dentro.

Darsela a gambe, dare in escandescenza, diventare bianco per la paura, diventare giallo di paura, diventare un demonio.

Essere morto/mezzo morto di paura, essere furibondo/una furia, essere fuori di sé, essere fuori dalla grazia di Dio, essere inferocito, essere contento come una Pasqua, essere fuori di sé dalla gioia, essere giù di corda/giri, (essere) innamorato cotto di. 
Fare fuoco e fiamme, farsela addosso, farsela sotto dalla paura, fuggire come una lepre, fuggire all'impazzata/come un fulmine/come un razzo, lasciarsi prendere dall'ira, fumare (di rabbia), montare in collera.

Prendere/prendersi una cotta per qualcuno, perdere il senno, perdere le staffe, toccare nel profondo.

Mettersi le gambe in spalla, montare il sangue alla testa, perdere il lume della ragione.

Non stare nella pelle (dalla gioia), non toccare terra dalla gioia, non avere più occhi.

Piangere a dirotto/a calde lacrime.

Rodersi dalla bile.

Scatenare la bufera, sembrare/vedere tutto rose e fiori, sentire le gambe fare giacomo giacomo, sentirsi rimescolare/torcere le budelle, sentire il collo in gola, spaventarsi a morte, spaventarsi per un nonnulla, sudare freddo, sprizzare rabbia dagli occhi.

Tremare di/per paura.

Uscire dai gangheri, urtare $i$ nervi.

Venire le lacrime agli occhi.

\subsubsection{El miedo/paura}

Expresan esta emoción en español e italiano las siguientes UFS:

Achantar el rabo, atravesársele/ponérsele a alguien un nudo en la garganta, ciscarse de miedo, encogérsele a alguien el ombligo,erizársele el cabello a alguien, estar muerto de miedo, helársele la sangre a alguien, huir como alma que lleva el diablo, írsele a alguien la sangre a los talones/a los zancajos, llevarse un susto padre, no llegarle a alguien la camisa al cuerpo, pillar un susto, poner los pies en polvorosa, quedarse helado, quedarse sin sangre, quedar petrificado de miedo, ponerse amarillo, ponerse pálido, ponerse blanco como la cera, ponerse blanco como el papel, ponérsele a alguien la carne de gallina, quedarse sin aliento, quedarse yerto, salir por pierna, salir con el rabo entre las piernas, sentir/tener sudores fríos, sudar de miedo, ser presa del pánico, tener el corazón en un puño, tenerlos por corbata, tomarle miedo (a alguien/a algo), temblar como un pajarito, temblar como una liebre cazada, temblar las carnes, tener un miedo cerval.

Acappare a rotta di collo/gambe, aver paura anche dell'aria, avere paura anche a respirare, avere/prendersi una fifa blu, avere paura della propria ombra, avere il cuore in gola, battere $i$ denti di/per la paura, da far paura, darsela a gambe, diventare bianco per la paura, diventare giallo di paura, essere morto/mezzo morto di paura, farsela addosso, farsela sotto dalla paura, fuggire come una lepre, fuggire all'impazzata/come un fulminel come un razzo, mettersi le gambe in spalla, sentire le gambe fare giacomo giacomo, sentirsi rimescolare/torcere le budelle, sentire il collo in gola, spaventarsi a morte, spaventarsi per un nonnulla, tremare di/per paura, sudare freddo.

\subsubsection{El amor}

Expresan esta emoción en español e italiano las siguientes UFS:

Beber los vientos por otra persona, brincarle dentro del pecho/del corazón, chiflarse/ chalarse por, estar colado, estar encoñado, entrar/llevar/sentir algo muy adentro, llegarle algo a alguien a las telas del corazón, perder la cabeza. 
Avere il batticuore, andare pazzo/matto per qualcuno, andare a carponi/a quattro zampe, arrivare/giungere al cuore, avere le chiavi del cuore di qualcuno, avere una cotta per qualcuno, battere il cuore, entrare dentro, (essere) innamorato cotto di, prendere/prendersi una cotta per qualcuno,toccare nel profondo.

\subsubsection{La Ira}

Expresan esta emoción en español e italiano las siguientes UFS:

Echar el bodegón por la ventana, echar fuego por los ojos, echar humo,echar rayos, echar venablos, (estar) hecho una fiera, echar espuma de rabia, escupir veneno y bilis, estar que echa rayos, llevarse a alguien el demonio/los demonios/todos los demonios, montar en cólera, ofenderse del aire, perder los estribos, ponerse de los nervios, poner negro a alguien una cosa, revolvérsele a alguien la bilis, sacar a alguien de sus casillas, sacar alguien de quicio, subirsele a alguien la sangre a la cabeza, tirar piedras, subirse a la parra.

Andare in bestia, avere il dente avvelenato con, avere un diavolo per capello, dare in escandescenza, diventare un demonio, essere furibondo/una furia, essere fuori di sé, essere fuori dalla grazia di Dio, essere inferocito, fare fuoco e fiamme, lasciarsi prendere dall'ira, fumare (di rabbia), montare in collera, montare il sangue alla testa, perdere il lume della ragione, perdere il senno, perdere le staffe, rodersi dalla bile, scatenare la bufera, sprizzare rabbia dagli occhi, uscire dai gangheri, andare su tutte le furie, urtare i nervi.

\subsubsection{Felicidad}

Expresan esta emoción en español e italiano las siguientes UFS:

Bailar en una pata (Can. Y Am.), dar alguien saltos/brincos de alegría/de contento, estar como unas castañuelas, no caber en sí, (tener) cara de aleluya, (ser) como niño con zapatos nuevos.

Essere contento come una Pasqua, essere fuori di sé dalla gioia, non stare nella pelle (dalla gioia), non toccare terra dalla gioia, sembrare/vedere tutto rose e fiori.

\subsubsection{Tristeza}

Expresan esta emoción en español e italiano las siguientes UFS:

Estar alguien hecho una Magdalena, llorar alguien a lágrima viva, llorar a moco tendido llorar como una Magdalena, saltársele a alguien las lágrimas.

Avere un nodo in gola, essere giù di corda/giri, non avere più occhi, piangere a dirotto/a calde lacrime, venire le lacrime agli occhi.

\subsection{Modelos icónicos y metáforas prevalentes}

El análisis llevado a cabo destaca que los modelos icónicos y metáforas que prevalecen en la descripción de la expresión de las emociones tenidas en cuenta en este trabajo son los siguientes: 


\subsubsection{Modelo icónico cuerpo + movimiento}

Archimetáforas:

a) Un movimiento corporal hacia abajo: achantar el rabo, irsele a alguien la sangre a los talones/a los zancajos, essere giù di corda/giri, non toccare terra dalla gioa.

b) Un movimiento corporal hacia arriba: erizársele el cabello a alguien, ponerse los pelos de punta, subirse a la parra, subirsele a alguien la sangre a la cabeza, tenerlos por corbata, avere il cuore in gola, montare il sangue alla testa.

c) Un movimiento corporar de huida: huir como alma que lleva el diablo, poner los pies en polvorosa, salir por pierna, salir con el rabo entre las piernas, acappare a rotta di collo/ gambe, dársela a gambe, fuggire all'ipazzata/come un fulmine/come un razzo, fuggire come una lepre, mettersi le gambe in spalla.

d) Un movimiento hacia adentro: Encogérsele el ombligo a alguien, entrar/llegar muy adentro, llegar a las telas del corazón, arrivare/giungere al cuore, entrare dentro/toccare nel profondo.

e) Un movimiento desde dentro del cuerpo hacia fuera, arrojar algo del propio cuerpo: echar fuego por los ojos, echar humo, echar rayos y centellas, o estar que echa rayos, echar venablos, tirar piedras, estar alguien hecho una Magdalena, llorar a lágrima viva, llorar como una Magdalena, saltársele a alguien las lágrimas, llorar a moco tendido, piangere a dirotto/a calde lacrime, sprizzare rabbia dagli occhi.

f) Un movimiento vibratorio en el cuerpo: brincarle dentro del pecho el corazón, dar alguien saltos/brincos de alegría, o de contento, temblar las carnes, temblar como un pajarito, temblar como una liebre cazada, avere il batticuore, battere il cuore, battere $i$ denti di/per la paura, tremare di/per paura.

g) Salir del propio cuerpo: essere fuori di sé dalla gioia, no caber en sí, non stare nella pelle (dalla gioia).

h) La ausencia de movimiento o parálisis: estar muerto de miedo, quedarse petrificado, quedarse yerto.

En este dominio hay que comentar la archimetáfora "el movimiento hacia arriba", que da lugar a metáforas que se basan en imágenes que pueden ser más o menos reales, ponerse los pelos de punta, o visionarias, tenerlos por corbata, que dan lugar a un movimiento ascendente en ambos casos.

\subsubsection{Modelo icónico cuerpo + cambio de temperatura:}

Archimetáforas:

a) Del calor al frío: helársele la sangre a alguien, quedarse helado, sudare freddo.

b) Del frío al calor: bullirle la sangre a alguien, estar que arde, ardere/infiammare d' ira, avere il sangue che bolle.

A partir del modelo icónico cuerpo + reacciones fisiológicas tenemos:

c) Reacciones fisiológicas: ciscarse de miedo, farsela addosso, farsela sotto dalla paura.

\subsubsection{Modelo icónico cuerpo + locura:}

Archimetáforas: 
a) Locura: perder la cabeza, andare pazzo/matto per qualcuno, essere fuori di sé, perdere il lume della ragione, perdere il senno.

\subsubsection{Modelo icónico Cuerpo + transformación:}

Archimetáforas:

a) Las emociones transforman al hombre: estar hecho un basilisco, estar hecho una fiera, ponérsele a alguien la carne de gallina, andare a carponi/a quattro zampe, andare in bestia, avere un diavolo per capello, diventare un demonio, essere un cane rabbioso, essere una belva/una bestia.

\subsubsection{Modelo icónico cuerpo + malestar interior:}

a) Las emociones provocan alteraciones violentas del cuerpo: atravesársele/ponérsele a alguien un nudo en la garganta, quedarse sin sangre, quedarse sin aliento, tener el corazón en un puño, diventare bianco per la paura, diventare giallo di paura, sentire le gambe fare giacomo giacomo, sentirse rimescolare/torcere le budelle, sentire il collo in gola.

\section{CONCLUSIÓN}

La clasificación y comparación de las UFS de los dos idiomas, español e italiano, a través de modelos icónicos prueba la existencia de una sistematicidad en los procesos que llevan a la producción de metáforas y UFS. Como entidades abstractas, las emociones pueden aprehenderse a partir de esquemas o parámetros más concretos tomados de la forma de concebir la realidad circundante, algo que descansa en aspectos cognitivos universales del cuerpo humano.

Ha de destacarse la variación en ambas lenguas de las partes del cuerpo que protagonizan las imágenes, con distintos grados de motivación o convencionalidad: alma, cabello, cabeza, carne, corazón, garganta, ojos, ombligo, pecho, pies, pierna, rabo, sangre, budelle, capello, collo, cuore, dente, denti, gambe, gola, occhi, pelle, spalla. Lo mismo ocurre con los animales: gallina, liebre, pajarito, lepre.

En cuanto a los verbos, destacamos: 1. verbos de cambio como ponerse y diventare, piezas clave en distintas UFS en ambas lenguas: ponerse de los nervios, diventare un demonio; 2. verbos que expresan el resultado de una acción, quedarse yerto; 3 . verbos que se refieren a acciones en movimiento como echar, entrar, llevarse, salir, andare, arrivare, fuggire, venire: echar fuego por los ojos/humo/rayos/venablos/espuma, salir por pierna, fuggire come una lepre, entrar algo muy adentro, arrivare/giungere al cuore, andare su tutte le furie, llevarse a alguien el demonio; dar saltos/brincos de alegría, venire le lacrime agli occhi. Señalamos la presencia de UFS en las que los verbos de movimiento atravesar, subir e ir se usan en forma reflexiva: atravesársele un nudo en la garganta, írsele la sangre a los talones, subirsele la sangre a la cabeza. Se repiten las UFS con verbos que expresan acciones en movimiento repetido y que tienen lugar dentro del propio cuerpo como temblar, battere o brincar: temblar como un pajarito, battere il cuore, brincarle dentro del pecho. Otras UFS contienen verbos que no expresan movimiento, con imágenes que se asocian a sensaciones o impresiones positivas: cara de aleluya, castañuelas, zapatos nuevos, Pasqua, rose e fiori. El amor está emparentado con el corazón y puede 
provocar un movimiento brusco de este: avere il batticuore, brincarle dentro del pecho el corazón, o un movimiento hacia dentro: llegar a las telas del corazón, entrar/llegar muy adentro, arrivare/giungere al cuore, entrare dentro/toccare nel profondo. Tales UFS se fundan en inferencias sistemáticas de patrones de correspondencia entre el dominio fuente y el dominio meta. Es, en definitiva, el corazón el contenedor de la emoción y la mejor evidencia de ello es la UF aprire il proprio cuore.

$\mathrm{Al}$ igual que otras emociones como el amor y la ira, el miedo es sentido como algo que se mueve o se transforma. En las dos lenguas se expresa mayormente a través de un modelo metafórico según el cual esta emoción se desplaza hacia un destino o entra en él: írsele a alguien la sangre a los talones, poner los pies en polvorosa, avere il cuore in gola, mettersi le gambe in spalla, llegarle algo a alguien a las telas del corazón, arrivare/giungere al cuore, subirse alguien a la parra.

Para concluir, las emociones tienen en español y en italiano un rico sistema fraseológico, muchas de las UFS se repiten en ambas lenguas en forma idéntica o muy parecida y resultan ser más motivadas y expresivas que cualquier término habilitado para la expresión de emociones.

\section{REFERENCIAS BIBLIOGRÁFICAS}

Casares, J. (1993). Introducción a la lexicografía moderna. Madrid: CSIC.

Chamizo Domínguez, P. (1989). "Metáfora, expresión y conocimiento". En Martín Vide, C. (Ed.), Actas del IV Congreso de Lenguajes Naturales y Lenguajes Formales. IV. 1. Barcelona: Promociones y Publicaciones Universitarias, pp. 283-308.

Chamizo Domínguez, P. (2005). "Variaciones representacionales y falsos amigos". En P. MartínezFreire (Ed.). Cognición y representación. Málaga: Suplementos de Contrastes, pp. 73-103.

Corpas Pastor, G. (2000). Las lenguas de Europa: estudios de fraseología y traducción. Granada: Comares.

Corpas Pastor, G. (1996). Manual de fraseología española. Madrid: Grados.

Coseriu, E. (1986). Introducción a la lingüística. Madrid: Gredos.

Deignan, A. (2003). "Metaphorical expressions and culture: An indirect link", Metaphor and Symbol, 18 , pp. 255-271.

Durante, V. (2014). Fraseología y paremiología: enfoques y aplicaciones. Madrid: Instituto Cervantes.

Duranti, A. (1997). Antropología Lingüistica. Madrid: Cambridge University Press.

Gibbs, Raymond W. (1992). "What do Idioms really mean?", Journal of Memory and Language, 31,485-506.

Gibbs, Raymond W. (1994). The Poetics of the Mind. Cambridge University Press.

Gibbs, R., Bogdanovich, J. Sykes, J. R. \& Barr, D. J. (1997). "Metaphor in Idiom Comprehension", Journal of Memory and Language, 37, pp. 141-154.

Gibbs, R. W (1999). "Researching Metaphor". En L. Cameon\& G. Low (Eds.). Researching and applying Metaphor.Cambridge: Cambridge University Press, pp. 29-47.

Iñesta Mena, E. M. \& Pamies Bertrán, A. (2002). Fraseología y metáfora: Aspectos tipológicos y cognitivos. Granada: Serie Granada Lingüística.

Jakobson, R. \& Halle, M.(1971). Fundamentals of Language. Mouton: The Hague.

Jäkel, O. (2002). "Hypotheses Revisited: The Cognitive Theory of Metaphor Applied to Religious Texts". metaphorik.de 02/2002, 20-42

Jakel O. (2003), Metafora $w$ abstrakcyjnych domenach dyskursu: kognitywno-lingwistyczna analiza metaforycznych modeli aktywności umysłowej, gospodarki i nauki (trad. di M. Banaś, B. Drąg), Kraków: Universitas 
Kövecses, Z. (2005). Metaphor in culture: universality and variation. Cambridge \&New York: Cambridge University Press.

Kvöecses, Z. (2010). Metaphor: A Practical Introduction. Oxford University Press.

Lakoff, G. \& Johnson, M. (1980). Metaphors we live by. Chicago: University of Chicago Press.

Lakoff, G. \& Johnson, M. (1998). Elementi di linguistica cognitiva. Urbino: Quattro Venti.

Lakoff, G. \& Johnson, M. (1998). Metafora e vita quotidiana. Milano: Bompiani.

Lakoff, G. \& Turner, M. (1989). More Than Cool Reason: A Field Guide to Poetic Metaphor. Chicago and London: The University of Chicago Press.

Lakoff, G. \& Johnson, M. (1999). Philosophy in the flesh. The embodied mind and its challenge to Western thought. New York: Basic Books.

Luque Durán, J. de Dios (2004). Aspectos universales y particulares del léxico de las lenguas del mundo. Granada: Impredisur.

Ortony, A. (1993). Metaphor and thought. Cambridge: Cambridge University Press.

Lakoff, George. (1987). Women, fire and dangerous things: what categories reveal about the mind. Chicago and London: The University of Chicago Press.

Lakoff, G..(1991). "Una figura del pensiero". En C. Cacciari (Ed.).Teorie della metafora. L'acquisizione, la comprensione e l'uso del linguaggio figurato.Milano: Raffaello Cortina Editore, pp. 215-228.

Molina Plaza, S. (2008). "Puntos de contacto e diferenza: a tradución de expresións idiomáticas e refráns metafóricos e metonímicos”, Cadernos de Fraseoloxía Galega, 10, pp. 207-2019.

Montoro del Arco, Esteban T. (2007). "La fraseología del vino. Per Abbat", Boletín filológico de actualización académica y didáctica, II, pp. 131-136.

Nubiola, J. (2000). "El valor cognitivo de las metáforas. Verdad, bien y belleza. Cuando los filósofos hablan de los valores", Cuadernos de Anuario Filosófico, 103, pp. 73-84.

Özçaliskan, S. (2003). "Metaphorical Motion in Crosslinguistic Perspective: A Comparison of English and Turkish",Metaphor and Symbol, v.18, n.3, pp. 189-228.

Pamies Bertrán, A. (2002)."Modelos icónicos y archimetáforas: algunos problemas metalingüísticos en el ámbito de la fraseología", Language Design 4, pp. 9-20.

PamiesBertrán, A. (2016) "Metafora grammaticale e metafora lessicale: implicazioni teoriche per la fraseologia". En Dal Maso, E.\&Navarro, C. (ed.). Guttacavatlapidem. Indagini fraseologiche e paremiologiche. Mantova: Universitas Studiorum, pp. 87-120.

Iñesta, E. \& Pamies, A. (2002). Fraseología y Metáfora. Granada: Método.

Penadés Martínez, I. (1999): "Para un tratamiento lexicográfico de las expresiones fijas irónicas desde la pragmática”, Pragmalingüistica, 7, pp. 185-210.

Rodríguez-Simón, F \& A. Pamies (1998) "La expresión de las sensaciones físicas". En Luque Durán, J. de Dios, y A. Pamies Bertrán (eds). Léxico y fraseología. Granada: Método, pp. 155-170.

Montoro del Arco, E. T. (2004): "La variación fraseológica y el diccionario". En Battaner, A. y DeCesaris, J. A., (eds.), De Lexicografia, pp. 591-604.

Ruiz Gurillo, L. (1997). “Aspectos de fraseología teórica española”, Cuadernos de Filología, Anejo XXIV.

Ruiz Gurillo, L. (2001). "La fraseología como cognición: vías de análisis”, LEA: Lingüística española actual, Vol. 23, No 1, pp. 107-132.

Samaniego Fernández, E. (1998). "Estudios sobre la metáfora", Espéculo, 8. Recuperado el 6 Septiembre, $2017 \mathrm{de}$ http://www.ucm.es/info/especulo/numero 8/e_saman1.html

Siqueira, M. S. G. \& Lamprecht, R. (2007). "As metáforas primárias na aquisição da linguagem: um estudo interlinguístico". DELTA. Documentação de Estudos em Lingüística Teórica e Aplicada, Vol. 23, pp. 245-272.

Taylor, John R. (2002). Cognitive Grammar. Oxford: Oxford University Press.

Wotjak, G. (1985). “Algunas observaciones acerca del significado de expresiones idiomáticas verbales en el español actual”, Anuario de Lingüística Hispánica, Vol. I, pp. 213-225.

Zuluaga Ospina, A., (1980). Introducción al estudio de las expresiones fijas. Frankfurt: Peter D. Lang. 